\title{
Theoretical analysis of a method for segmented heat exchanger design
}

\author{
SONG JiWei, XU MingTian \& CHENG Lin* \\ Institute of Thermal Science and Technology, Shandong University, Jinan 250061, China
}

Received November 2, 2010; accepted March 9, 2011

\begin{abstract}
In the process of the design of heat exchangers, it is difficult to establish the factors governing the optimal points of the design objective functions due to the contradictions and uncertainties of the design objectives. The variation of fluid properties is one of the main factors causing this type of uncertainty. Conventional design methods have not completely solved these problems. In the present work, based on the logarithmic mean temperature difference, a new heat exchanger design method (called the segmented design method) is proposed which takes into account the variation of fluid properties with respect to the temperature. In this method, the whole heat exchanger is first divided into several segments. Then by applying the principle of the conservation of energy and taking into account the initial conditions as well as the connecting conditions of the adjacent segments, the inlet and outlet temperatures of each segment are determined. Finally, the application of the logarithmic mean temperature difference method on each segment defines the heat transfer area.
\end{abstract}

heat exchanger, thermal design, mean temperature difference

Citation: $\quad$ Song J W, Xu M T, Cheng L. Theoretical analysis of a method for segmented heat exchanger design. Chinese Sci Bull, 2011, 56: 2179-2184, doi: $10.1007 / \mathrm{s} 11434-011-4462-7$

In the process of the design of heat exchangers, it is difficult to determine the set of optimal points for the design objective functions due to the contradictions and uncertainties among the design objectives, which makes it difficult to apply the modern computing technology. The variation of fluid properties with respect to temperature in heat exchangers is one of the main factors causing this situation.

For conventional design methods of heat exchangers, such as the logarithmic mean temperature difference (LMTD), efficiency-number transfer unit( $\varepsilon$-NTU), etc., the value of fluid properties is usually supposed to be constant. For fluids which have physical properties that show no significant changes with temperature variation, such as non-saturated water, the physical parameters may be assumed to be constant and to equal their mean value. This treatment can usually satisfy the design requirements. Nevertheless, it is not consistent with the reality of the heat

*Corresponding author (email: cheng@sdu.edu.cn) transfer process. In particular, in many engineering applications the fluid properties in heat exchangers experience significant variation with temperature and pressure, such as in the petrochemical industry. In these cases, to make the physical parameters take their mean values gives rise to inaccurate design results. Moreover, in some low temperature heat exchangers, there are relatively large temperature differences between their inlets and outlets, so the variation of fluid properties cannot be ignored [1]. To improve the design of heat exchangers, especially the shell-tube heat exchangers, some new ideas were proposed in [2]. The optimized designs of heat exchangers were investigated in [3, 4], but there is still significant scope for improving the description of the heat exchange process in the heat exchanger. Thus, how to account for the variation of the physical parameters with the temperature is not only one important approach for improving heat exchanger design, but also an important measure for the design of highly efficient and low-consumption heat exchangers. 
Taking into account the dependence of fluid properties on temperature inside heat exchangers, Chato proposed the temperature transfer matrix method for rating heat exchanger [5]. Paffenbarger analyzed the heat transfer process in the counter flow plate-fin heat exchangers with variable fluid properties using the finite element method [6]. Roetzel and Spang gave a step-by-step procedure for computing the overall heat transfer coefficient when the specific heat at constant pressure varies with the temperature [7]. Later, based on the $\varepsilon$-NTU method, Shah and Sekulić improved this method and put forward a numerical method for checking heat exchanger design which considered the non-uniformity of fluid velocity and variation of fluid properties with temperature [8,9]. Skoglund et al. applied the finite volume method to the numerical analysis of the flow and heat transfer in heat exchangers with variable fluid properties [1].

In this paper, based on the LMTD method, a segmented heat exchanger design method is proposed taking into account the dependence of the specific heat at a constant pressure on the temperature. The thermal design of counter and parallel flow heat exchangers are discussed.

\section{The segmented heat exchanger design method}

In heat exchanger design, it is impractical to account for the exact variation of the fluid physical parameters with respect to the temperature. This would make the design process too complicated to handle. However, it is possible to describe the variable physical parameters approximately. To do this, we divide the whole heat exchanger into finite segments. For each segment, we assume that the fluid physical parameters are constant and the mean temperature is employed to determine the values of the physical parameters. Using the principle of the conservation of energy, the connecting conditions between the adjacent segments are established which can subsequently be applied to determine the inlet and outlet temperatures. For each segment, the LMTD method can be utilized to compute the heat exchange area. Thus, the thermal design of the heat exchanger is completed. It was clear that compared with conventional design methods, our design results were closer to reality and thus more accurate.

In the following discussion, we ignore the longitudinal heat conduction in the heat exchanger and assume the variation rule of fluid properties with temperature. In addition, we assume the overall heat transfer coefficient, the inlet temperature of the hot fluid and the outlet temperature of the cold fluid are known. The design objective is to compute the heat transfer area.

\subsection{The segmented design for the parallel flow heat exchanger}

For a parallel flow heat exchanger as shown in Figure 1, the whole heat exchanger is divided into two segments, and the fluid physical parameters of each segment are regarded as constant.

$T_{h, i}$ is the inlet temperature of the hot fluid, $T_{c, i}$ is the inlet temperature of the cold fluid, $T_{c, o}$ is the specified outlet temperature of the cold fluid, $C_{h}^{(1)}$ and $C_{c}{ }^{(1)}$ are the thermal capacities of the hot and the cold fluids of the first segment, $U_{1}$ is the overall heat transfer coefficient of the first segment, and $C_{h}^{(2)}, C_{c}^{(2)}$ and $U_{2}$ are the corresponding parameters of the second segment. Assuming that the cold fluid absorbs all the heat released by the hot fluid, we obtain

$$
q=\int_{i}^{o} \mathrm{~d} q=-\int_{i}^{o} \mathrm{~d}\left(C_{h} T_{h}\right)=\int_{i}^{o} \mathrm{~d}\left(C_{c} T_{c}\right) .
$$

Here, $q$ is the heat load.

From eq. (1), we obtain

$$
C_{h}^{(1)} T_{h, i}-C_{h}^{(2)} T_{h, o}=C_{c}^{(2)} T_{c, o}-C_{c}^{(1)} T_{c, i} .
$$

Furthermore, eq. (2) allows us to express the outlet temperature of the hot fluid as follows:

$$
T_{h, o}=\frac{C_{h}^{(1)}}{C_{h}^{(2)}} T_{h, i}-\frac{C_{c}^{(2)}}{C_{h}^{(2)}} T_{c, o}+\frac{C_{c}^{(1)}}{C_{h}^{(2)}} T_{c, i} .
$$

The assumption that the heat released from the hot fluid can be completely absorbed by the cold fluid on each segment leads to

$$
\left\{\begin{array}{l}
C_{h}{ }^{(1)}\left(T_{h, i}-T_{h, o}{ }^{(1)}\right)=C_{c}{ }^{(1)}\left(T_{c, o}{ }^{(1)}-T_{c, i}\right), \\
C_{h}{ }^{(2)}\left(T_{h, o}{ }^{(1)}-T_{h, o}\right)=C_{c}{ }^{(2)}\left(T_{c, o}-T_{c, o}{ }^{(1)}\right),
\end{array}\right.
$$

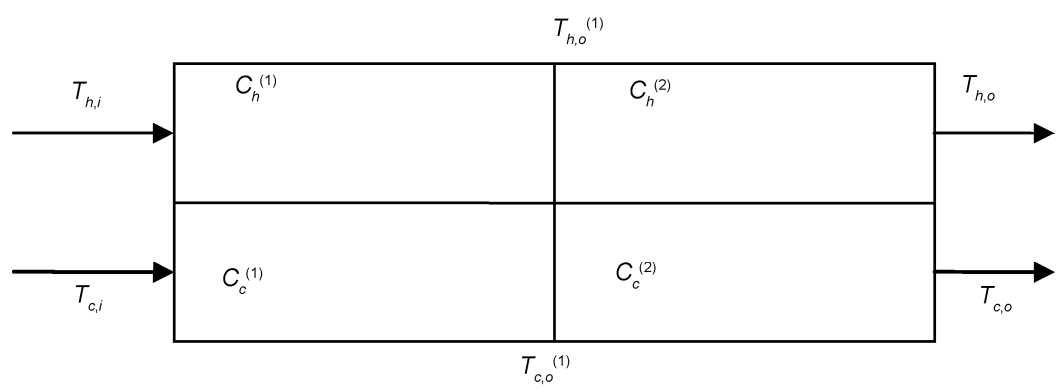

Figure 1 Segment sketch for parallel flow heat exchanger. 
where $T_{c, o}{ }^{(1)}$ and $T_{h, o}{ }^{(1)}$ are the outlet temperatures of the cold and hot fluids of the first segment, and are also the inlet temperatures of the cold and hot fluids of the second segment. The above equation can be rewritten as follows:

$$
\left\{\begin{array}{l}
C_{C}{ }^{(1)} T_{c, o}{ }^{(1)}+C_{h}{ }^{(1)} T_{h, o}{ }^{(1)}=T_{h c, i}{ }^{(1)}, \\
C_{c}{ }^{(2)} T_{c, o}{ }^{(1)}+C_{h}{ }^{(2)} T_{h, o}{ }^{(1)}=T_{h c, o}{ }^{(2)},
\end{array}\right.
$$

where $T_{h c, i}{ }^{(1)}=C_{h}{ }^{(1)} T_{h, i}+C_{c}{ }^{(1)} T_{c, i}, T_{h c, o}{ }^{(2)}=C_{c}{ }^{(2)} T_{c, o}+C_{h}{ }^{(2)} \mathrm{T}_{h, o}$.

Solving eq. (4) for the system yields

$$
T_{c, o}{ }^{(1)}=\frac{\left|\begin{array}{ll}
T_{h c, i}{ }^{(1)} & C_{h}{ }^{(1)} \\
T_{h c, o}{ }^{(2)} & C_{h}^{(2)}
\end{array}\right|}{\left|\begin{array}{ll}
C_{c}^{(1)} & C_{h}^{(1)} \\
C_{c}^{(2)} & C_{h}^{(2)}
\end{array}\right|}, T_{h, o}{ }^{(1)}=\frac{\left|\begin{array}{ll}
C_{c}^{(1)} & T_{h c, i}{ }^{(1)} \\
C_{c}^{(2)} & T_{h c, o}{ }^{(2)}
\end{array}\right|}{\left|\begin{array}{ll}
C_{c}^{(1)} & C_{h}{ }^{(1)} \\
C_{c}^{(2)} & C_{h}{ }^{(2)}
\end{array}\right|}
$$

where $\frac{C_{h}^{(2)}}{C_{h}^{(1)}} \neq \frac{C_{c}^{(2)}}{C_{c}^{(1)}}$.

Eq. (4) has only one solution. Thus, the outlet temperature of first segment in the case of parallel fluid, which is the same as the inlet temperature of second segment, can be obtained. Using the LMTD method establishes the heat transfer area of each segment of the heat exchanger. By the definition, the logarithmic mean temperature difference of the first segment can be written as follows [10]:

$$
\Delta T_{l m}{ }^{(1)}=\frac{\Delta T_{2}^{(1)}-\Delta T_{1}^{(1)}}{\ln \Delta T_{2}^{(1)}-\ln \Delta T_{1}^{(1)}} .
$$

Here, $\Delta T_{1}^{(1)}=T_{h, l}-T_{c, i}, \Delta T_{2}^{(1)}=T_{h, o}{ }^{(1)}-T_{c, o}{ }^{(1)}$.

Assuming $q_{1}$ is heat load of the first segment, we obtain:

$$
\begin{aligned}
q_{1} & =U_{1} A_{1} \Delta T_{l m}{ }^{(1)}=C_{h}{ }^{(1)}\left(T_{h, i}-T_{h, o}{ }^{(1)}\right) \\
& =C_{c}{ }^{(1)}\left(T_{c, o}{ }^{(1)}-T_{c, i}\right) .
\end{aligned}
$$

Using eq. (6), the first segment heat transfer area can be computed as follows:

$$
A_{1}=\frac{C_{h}^{(1)}\left(T_{h, i}-T_{h, o}{ }^{(1)}\right)}{U_{1} \Delta T_{l m}{ }^{(1)}}=\frac{C_{c}^{(1)}\left(T_{c, o}{ }^{(1)}-T_{c, i}\right)}{U_{1} \Delta T_{l m}{ }^{(1)}} .
$$

Using the same method, the second segment heat transfer area can be computed as follows:

$$
A_{2}=\frac{C_{h}{ }^{(2)}\left(T_{h, o}{ }^{(1)}-T_{h, o}\right)}{U_{2} \Delta T_{l m}{ }^{(2)}}=\frac{C_{c}{ }^{(2)}\left(T_{c, o}-T_{c, o}{ }^{(1)}\right)}{U_{2} \Delta T_{l m}{ }^{(2)}} .
$$

Here,

$$
\begin{aligned}
& \Delta T_{1}^{(2)}=T_{h, o}{ }^{(1)}-T_{c, o}{ }^{(1)}, \Delta T_{2}^{(2)}=T_{h, o}-T_{c, o}, \\
& \Delta T_{l m}{ }^{(2)}=\frac{\Delta T_{2}^{(2)}-\Delta T_{1}^{(2)}}{\ln \Delta T_{2}^{(2)}-\ln \Delta T_{1}^{(2)}} .
\end{aligned}
$$

The above accounts for variation of fluid physical parameters, and gives the segmented design method when dividing the whole heat exchanger into two segments.

When there are relatively big temperature differences between the inlet and outlet of the cold and hot fluids, dividing the heat exchanger into two segments cannot exactly describe the variation of thermal capacity with temperature. In this case, it is necessary to divide the heat exchanger into $n$ segments (the number of $n$ can be chosen based on the actual case, such as $2,3,4,5 \ldots n)$. Here, the design method is the same as when dividing the heat exchanger into two segments. We assume that the inlet temperature of hot fluid $T_{h, i}$, the inlet temperature of cold fluid $T_{c, i}$, the appointed outlet temperature of cold fluid $T_{c, o}$, the thermal capacity of hot and cold fluid of each segment $C_{h}{ }^{(i)}$ and $C_{c}{ }^{(i)}(\mathrm{i}=1,2, \ldots n)$, and the heat transfer coefficient $U_{i}$ are known, and also that cold fluid absorbs the heat released by hot fluid.

By eq. (1) the outlet temperature of hot fluid can be obtained as follows:

$$
T_{h, o}=\frac{C_{h}^{(1)}}{C_{h}{ }^{(n)}} T_{h, i}-\frac{C_{c}^{(n)}}{C_{h}^{(n)}} T_{c, o}+\frac{C_{c}^{(1)}}{C_{h}{ }^{(n)}} T_{c, i} .
$$

In the case in which the cold fluid of each segment absorbs the heat released by the hot fluid of the same segment, we obtain

$$
\left\{\begin{array}{l}
C_{h}{ }^{(i)}\left(T_{h, o}{ }^{(i-1)}-T_{h, o}{ }^{(i)}\right)=C_{c}{ }^{(i)}\left(T_{c, o}{ }^{(i)}-T_{c, o}{ }^{(i-1)}\right) \\
(i=1,2, \cdots, n-1), \\
C_{h}^{(i-1)} T_{h, o}{ }^{(i-1)}-C_{h}{ }^{(i+1)} T_{h, o}{ }^{(i)} \\
=C_{c}{ }^{(i+1)} T_{c, o}{ }^{(i)}-C_{c}{ }^{(i-1)} T_{c, o}{ }^{(i-1)},(i=2,3, \cdots, n-1) \\
C_{h}{ }^{(n)}\left(T_{h, o}{ }^{(n-1)}-T_{h, o}\right)=C_{c}{ }^{\left({ }^{(}\right)}\left(T_{c, o}-T_{c, o}{ }^{(n-1)}\right) .
\end{array}\right.
$$

Here, $T_{h, o}{ }^{(0)}=T_{h, i}$ and $T_{c, o}{ }^{(0)}=T_{c, i}$. Eq. (10) may be rewritten as eq. (11).

$$
\left(\begin{array}{ll}
D_{1} & D_{2} \\
D_{3} & D_{4}
\end{array}\right)\left(\begin{array}{l}
T_{c} \\
T_{h}
\end{array}\right)=B
$$

Here, $T_{c}=\left(T_{c, o}{ }^{(1)}, T_{c, o}{ }^{(2)}, \cdots, T_{c, o}{ }^{(\mathrm{n}-1)}\right)^{T}$ and $T_{h}=\left(T_{h, o}{ }^{(1)}, T_{h, o}{ }^{(2)}, \cdots\right.$, $\left.T_{h, o}{ }^{(\mathrm{n}-1)}\right)^{T}$,

$$
\begin{gathered}
B=\left(B_{i}\right), \\
D_{1}=\left(D_{1}(i, j)\right)_{(n-1) \times(n-1)}, \\
D_{2}=\left(D_{2}(i, j)\right)_{(n-1) \times(n-1)}, \\
D_{3}=\left(D_{3}(i, j)\right)_{(n-1) \times(n-1)}, \\
D_{4}=\left(D_{4}(i, j)\right)_{(n-1) \times(n-1)} .
\end{gathered}
$$

These Matrix components are

$$
\begin{gathered}
B_{1}=C_{h}^{(1)} T_{h, i}+C_{c}^{(1)} T_{c, i}, \\
B_{i}=0,(i=2,3, \cdots, 2 n-3), \\
B_{2 n-2}=C_{c}^{\left({ }^{(n)}\right.} T_{c, o}+C_{h}^{(n)} T_{h, o}, \\
D_{1}(1,1)=C_{c}^{(1)},
\end{gathered}
$$




$$
\begin{gathered}
D_{1}(i, j)=\left\{\begin{array}{l}
C_{c}^{(i)}, j=i-1 \\
-C_{c}^{(i)}, j=i,(i=2,3, \cdots, n-1), \\
0, j \neq i-1, j \neq i
\end{array}\right. \\
D_{2}(1,1)=C_{h}^{(1)}, \\
D_{2}(i, j)=\left\{\begin{array}{l}
C_{h}^{(i)}, j=i-1 \\
-C_{h}^{(i)}, j=i,(i=2,3, \cdots, n-1), \\
0, j \neq i-1, j \neq i
\end{array}\right. \\
D_{3}(i, j)=\left\{\begin{array}{l}
C_{c}^{(i)}, j=i \\
-C_{c}^{(i+2)}, j=i+1,(i=1,2, \cdots, n-2), \\
0, j \neq i, j \neq i+2
\end{array}\right. \\
D_{3}(n-1, j)=\left\{\begin{array}{l}
C_{c}^{(n)}, j=n-1 \\
0, j \neq n-1
\end{array},(i=1,2, \cdots, n-1),\right. \\
D_{4}(i, j)=\left\{\begin{array}{l}
C_{h}^{(i)}, j=i \\
-C_{h}^{(i+2)}, j=i+1,(i=1,2, \cdots, n-2), \\
0, j \neq i, j \neq i+2
\end{array},\right. \\
D_{4}(n-1, j)=\left\{\begin{array}{l}
C_{h}^{(n)}, j=n-1 \\
0,
\end{array},(i=n-1,2, \cdots, n-1) .\right.
\end{gathered}
$$

where, $\left|\begin{array}{cc}D_{1} & D_{2} \\ D_{3} & D_{4}\end{array}\right| \neq 0$.

Eq. (11) has only one solution. Thus the outlet and inlet temperatures of each segment can be computed, and the logarithmic mean temperature difference of each segment can be also obtained as follows:

$$
\begin{aligned}
& \Delta T_{l m}{ }^{(i)}=\frac{\Delta T_{2}^{(i)}-\Delta T_{1}^{(i)}}{\ln \Delta T_{2}^{(i)}-\ln \Delta T_{1}^{(i)}}, \\
& \Delta T_{1}^{(i)}=T_{h, o}{ }^{(i-1)}-T_{c, o}{ }^{(i-1)}, \Delta T_{2}^{(i)} \\
& =T_{h{ }^{(i)}}{ }^{(i)} T_{c, o}{ }^{(i)},(i=1,2, \cdots, n), \\
& T_{h, o}{ }^{(o)}=T_{h, i}, T_{c, o}{ }^{(0)}=T_{c, i}, T_{h, o}{ }^{(n)} \\
& =T_{h, o}, T_{c, o}{ }^{(n)}=T_{c, o} .
\end{aligned}
$$

Consequently, the heat transfer area $A_{i}$ of each segment can be computed as follows:

$$
\begin{aligned}
& A_{i}=\frac{C_{h}{ }^{(i)}\left(T_{h, o}{ }^{(i-1)}-T_{h, o}{ }^{(i)}\right)}{U_{i} \Delta T_{l m}{ }^{(i)}}=\frac{C_{c}{ }^{(i)}\left(T_{c, o}{ }^{(i)}-T_{c, o}{ }^{(i-1)}\right)}{U_{i} \Delta T_{l m}{ }^{(i)}}, \\
& i=1,2, \cdots, n .
\end{aligned}
$$

Thus, the segmented parallel flow heat exchanger design is completed accounting for the variation of $C_{p}$ with temperature.

\subsection{The segmented design for counter flow heat exchanger}

For the counter flow heat exchanger as shown in Figure 2, the whole heat exchanger is divided into two segments, and the fluid physical parameters of each segment are regarded as constant. $T_{h, i}$ is the inlet temperature of the hot fluid, $T_{c, i}$ is the inlet temperature of the cold fluid, $T_{c, o}$ is the appointed outlet temperature of the cold fluid, $C_{h}^{(1)}$ and $C_{c}^{(1)}$ are the thermal capacity of the hot and cold fluids, $U_{1}$ is the overall heat transfer coefficient of the first segment, and $C_{h}{ }^{(2)}, C_{c}{ }^{(2)}$ and $U_{2}$ are the corresponding parameter of the second segment. We assume the cold fluid absorbs all the heat released by the hot fluid.

Using eq. (1), we obtain

$$
C_{h}^{(1)} T_{h, i}-C_{h}^{(2)} T_{h, o}=C_{c}^{(1)} T_{c, o}-C_{c}^{(2)} T_{c, i} .
$$

Using the same method as in Section 1.1 yields

$$
T_{h, o}{ }^{(1)}=\frac{\left|\begin{array}{ll}
T_{h c}{ }^{(1)} & -C_{c}^{(1)} \\
T_{h c}^{(2)} & -C_{c}^{(2)}
\end{array}\right|}{\left|\begin{array}{ll}
C_{h}^{(1)} & -C_{c}^{(1)} \\
C_{h}{ }^{(2)} & -C_{c}^{(2)}
\end{array}\right|}, T_{c, o}{ }^{(1)}=\frac{\left|\begin{array}{ll}
C_{h}{ }^{(1)} & T_{h c}{ }^{(1)} \\
C_{h}^{(2)} & T_{h c}{ }^{(2)}
\end{array}\right|}{\left|\begin{array}{ll}
C_{h}^{(1)} & -C_{c}^{(1)} \\
C_{h}^{(2)} & -C_{c}^{(2)}
\end{array}\right|} .
$$

The logarithmic mean temperature difference of the first segment can be obtained as follows:

$$
\Delta T_{l m}^{(1)}=\frac{\Delta T_{2}^{(1)}-\Delta T_{1}^{(1)}}{\ln \Delta T_{2}^{(1)}-\ln \Delta T_{1}^{(1)}} .
$$

Here, $\Delta T_{1}^{(1)}=T_{h, i}-T_{c, o}, \quad \Delta T_{2}^{(1)}=T_{h, o}{ }^{(1)}-T_{c, o}{ }^{(1)}$.

Thus, the heat transfer area $A_{1}$ is obtained as follows:

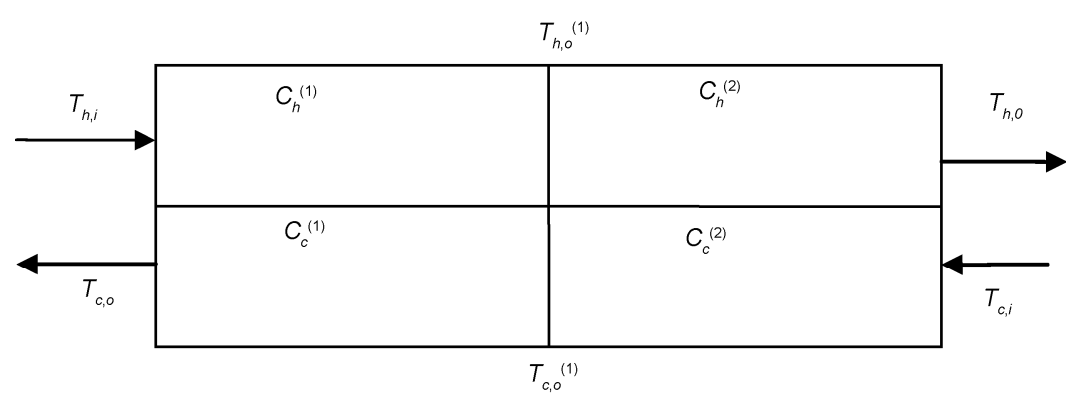

Figure 2 Segment sketch for counter flow heat exchanger. 


$$
A_{1}=\frac{C_{h}^{(1)}\left(T_{h, i}-T_{h, o}{ }^{(1)}\right)}{U_{1} \Delta T_{l m}{ }^{(1)}}=\frac{C_{c}^{(1)}\left(T_{c, o}-T_{c, o}{ }^{(1)}\right)}{U_{1} \Delta T_{l m}{ }^{(1)}} .
$$

The second segment heat transfer area $A_{2}$ is also obtained as follows:

$$
A_{2}=\frac{C_{h}^{\left({ }^{(2)}\right.}\left(T_{h, o}{ }^{(1)}-T_{h, o}\right)}{U_{2} \Delta T_{l m}{ }^{(2)}}=\frac{C_{c}^{(2)}\left(T_{c, o}{ }^{(1)}-T_{c, i}\right)}{U_{2} \Delta T_{l m}{ }^{(2)}} .
$$

Here, $\Delta T_{1}^{(2)}=T_{h, o}{ }^{(1)}-T_{c, i}, \Delta T_{2}^{(2)}=T_{h, o}-T_{c, i}$.

When the thermal capacity varies acutely with temperature, dividing the heat exchanger into two segments is not enough to describe the actual heat transfer process. It is necessary to divide the heat exchangers into $n$ segments (the number of $n$ can be chosen as $2,3,4,5 \ldots n)$. In this case, the design method is the same as mentioned above. Assuming that the inlet temperature of the hot fluid $T_{h, i}$, the inlet temperature of the cold fluid $T_{c, i}$, the appointed outlet temperature of the cold fluid $T_{c, o}$, the thermal capacity of the hot and cold fluids of each segment $C^{(i)}{ }_{h}$ and $C^{(i)}{ }_{c}(i=1,2 \ldots n)$, and the overall heat transfer coefficients $U_{i}$ are all known, and that the cold fluid of each segment absorbs heat released by the hot fluid of the same segment, we obtain

$$
\left\{\begin{array}{l}
-C_{c}{ }^{(i)} T_{c, o}{ }^{(i-1)}+C_{c}{ }^{(i)} T_{c, o}{ }^{(i)}+C_{h}{ }^{(i)} T_{h, o}{ }^{(i-1)} \\
-C_{h}{ }^{(i)} T_{h, o}{ }^{(i)}=0, i=1,2, \cdots, n-1, \\
-C_{c}^{(i-1)} T_{h, o}{ }^{(i-1)}+C_{c}{ }^{(i+1)} T_{c, o}{ }^{(i)}+C_{h}{ }^{(i-1)} T_{h, o}{ }^{(i-1)} \\
-C_{h}^{(i+1)} T_{h, o}{ }^{(i)}=0, i=1,2, \cdots, n-2, \\
-C_{c}^{\left({ }^{(n-1)}\right.} T_{c, o}{ }^{(n-1)}+C_{c}{ }^{(n)} T_{c, i} \\
+C_{h}{ }^{(n-1)} T_{h, o}{ }^{(n-1)}-C_{h}{ }^{(n)} T_{h, o}=0 .
\end{array}\right.
$$

Here, $T_{h, o}{ }^{(0)}=T_{h, i}, T_{c, o}{ }^{(0)}=T_{c, o}$.

By the method outlined in Section1.1, we obtain

$$
\Delta T_{l m}{ }^{(i)}=\frac{\Delta T_{2}^{(i)}-\Delta T_{1}^{(i)}}{\ln \Delta T_{2}^{(i)}-\ln \Delta T_{1}^{(i)}},(i=1,2, \cdots, n) .
$$

Here, $\Delta T_{1}^{(i)}=T_{h, o}{ }^{(i-1)}-T_{c, o}{ }^{(i-1)}, \Delta T_{2}{ }^{(i)}=T_{h, o}{ }^{(i)}-T_{c, o}{ }^{(i)}$.

Consequently, the heat transfer area of each segment can be obtained as follows:

$$
\begin{aligned}
& A_{i}=\frac{C_{h}{ }^{(i)}\left(T_{h, o}{ }^{(i-1)}-T_{h, o}{ }^{(i)}\right)}{U_{i} \Delta T_{l m}{ }^{(i)}}=\frac{C_{c}{ }^{(i)}\left(T_{c, o}{ }^{(i-1)}-T_{c, o}{ }^{(i)}\right)}{U_{i} \Delta T_{l m}{ }^{(i)}}, \\
& (i=1,2, \cdots, n) .
\end{aligned}
$$

Thus, the segmented counter flow heat exchanger design is completed taking into account the variation of $C_{p}$ with temperature.

\section{Example}

In this paper, an E type shell-tube heat exchanger is designed to achieve cooling of the engine oil from $420 \mathrm{~K}$ to $360 \mathrm{~K}$ with cold water at an initial temperature of $290 \mathrm{~K}$. In the heat exchanger, the cold water flows in the shell at a velocity of $1.4 \mathrm{~kg} / \mathrm{s}$, and the oil flows in the tubes at a velocity of $1.0 \mathrm{~kg} / \mathrm{s}$. We assume the heat transfer coefficient of heat exchanger is $225 \mathrm{~W} / \mathrm{m}^{2}$, and compute the heat transfer area of this heat exchanger. Here the $c_{p}$ of the cold water and oil is shown in [11]. As shown in Figure 3, the variation of $c_{p}$ with respect to temperature cannot be ignored.

During the design process, using the segmented method proposed above, we divided the whole heat exchanger into two and three segments, and compared the results with those obtained using the conventional LMTD and $\varepsilon$-NTU method. The data are shown in Table 1.

The results obtained using the conventional LMTD and $\varepsilon$-NTU methods are the same, but differences exist with the results obtained with the segmented design method. The main reason for this is that the differences between the local fluid physical parameters and the mean physical parameters lead to the difference in the quantities of heat transfer, which influences the designed values of the local heat transfer area. Here $c_{p}$ is the main influencing factor. In the design process which divides the heat exchanger into two segments, $390 \mathrm{~K}$ is chosen as the dividing point in the de-

\begin{tabular}{|c|c|c|c|c|c|c|}
\hline & \multicolumn{3}{|c|}{ Conventional design method } & \multicolumn{3}{|c|}{ Segmented design method } \\
\hline & LMTD & $\varepsilon-\mathrm{NTU}$ & 2 segments & Difference $(\%)$ & 3 segments & Difference (\%) \\
\hline Heat transfer area (parallel flow) $\left(\mathrm{m}^{2}\right)$ & 7.531 & 7.531 & 7.491 & 0.53 & 7.485 & 0.61 \\
\hline Heat transfer area (counter flow) $\left(\mathrm{m}^{2}\right)$ & 7.032 & 7.032 & 6.997 & 0.50 & 6.991 & 0.58 \\
\hline
\end{tabular}
sign. Compared with the results obtained with the LMTD method, it has some differences, which also influences the

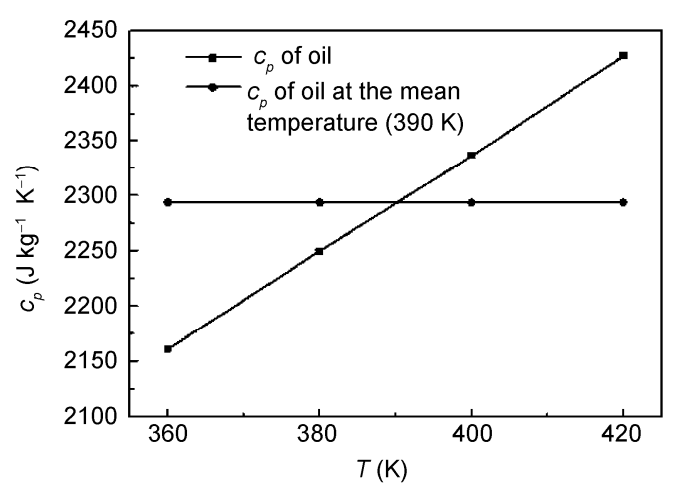

Figure $3 c_{p}$ of oil with respect to temperature.

Table 1 Heat transfer area 
exact level obtained for designing the heat transfer area. For the case when the heat exchanger is divided into three segments, the same differences exist, and are bigger near the inlet and outlet, which is appropriate for the actual process. When the number of segments is sufficiently large, using the corresponding program and software, the design is more exact. Thus, the original investment could obviously be reduced in the field of engineering.

The use of segmented design for heat exchangers has been adopted in some fields of engineering. In some cases, the heat transfer area could be reduced by about $10 \%$ compared with conventional design methods.

\section{Conclusions}

In this paper, the heat exchanger segmented design method is discussed taking into account the variation of $c_{p}$ with respect to temperature. Dividing the heat exchanger into finite segments, assuming the physical parameters of each segment are constant, and using the connection conditions of adjacent segments and the conservation of energy principle, the inlet and outlet temperature of each segment can be obtained. Applying the LMTD method then enabled the heat transfer area of each segment to be computed, so the whole design was complete. Theoretically, the result obtained with the segmented design method is more exact and consistent with real situations. In this paper, it has been shown that the segmented design method can be used for shell-tube heat exchangers design. However, for plate-fin and other across flow heat exchangers designs, using the segmented design method is more complicated, which requires further research.

Furthermore, the segmented design of the whole process of heat transfer in heat exchangers is not only a method for designing the local area more exactly, but also for obtaining the local heat transfer capacity, temperature properties and the local temperature differences more exactly, which provides an approach for heat exchanger optimization design.

This work was supported by the National Basic Research Program of China (2007CB206900), the International Science and Technology Cooperation Program of Shandong Province (2008GJHZ20701), and the Science and Technology Development Program of Shandong Province (2009GG2ZC07006).

1 Skoglund T, Arzen K-E, Dejmek P. Dynamic object-oriented heat exchanger models for simulation of fluid property transitions. Int $\mathbf{J}$ Heat Mass Transfer, 2006, 49: 2291-2303

2 Cheng L, Luan T, Du W J, et al. Heat transfer enhancement by flow-induced vibration in heat exchangers. Int J Heat Mass Transfer, 2009, 52: 1053-1057

3 Guo J F, Xu M T, Cheng L. Principle of equipartition of entransy dissipation for heat exchanger design. Sci China Tech Sci, 2010, 53: 1309-1314

4 Guo J F, Xu M T, Cheng L. The entransy dissipation minimization principle under given heat duty and heat transfer area conditions. Chinese Sci Bull, 2010, 55: 3141-3146

5 Chato J C, Leverman R J, Shah J M. Analysis of parallel flow multistream heat exchangers. Int J Heat Mass Transfer, 1971, 14: 1691-1703

6 Paffenbarger M. General computer analysis of multistream plate fin heat exchanger. In: Shah R K, Krause A D, Etzger D M, eds. Compact Heat Exchanger-A Festschrift for London A L. New York: Hemisphere Publishing, 1990. 727-746

7 Roetzel W, Spang B. Design of heat exchangers. In: VDI, VDI-GVC. VDI Heat Atlas. Dusseldorf: VDI-Verlag, 1993

8 Sekulć D P, Shah R K. Thermal design theory of three-fluid heat exchanger. Adv Heat Exchanger, 1995, 26: 219-327

9 Shah R K, Sekulć D P. Nonuniform heat transfer coefficients in conventional heat exchanger design theory. ASME J Heat Transfer, 1998, 119: 520-525

10 Incropera F P, Dewitt D P. Fundamentals of Heat and Mass Transfer. New York: John Wiley \& Sons, Inc., 1996

11 Shah R K, Sekulć D P. Fundamentals of Heat Exchangers Design (in Chinese). Cheng L, Trans. Beijing: China Machine Press, 2010

Open Access This article is distributed under the terms of the Creative Commons Attribution License which permits any use, distribution, and reproduction in any medium, provided the original author(s) and source are credited. 